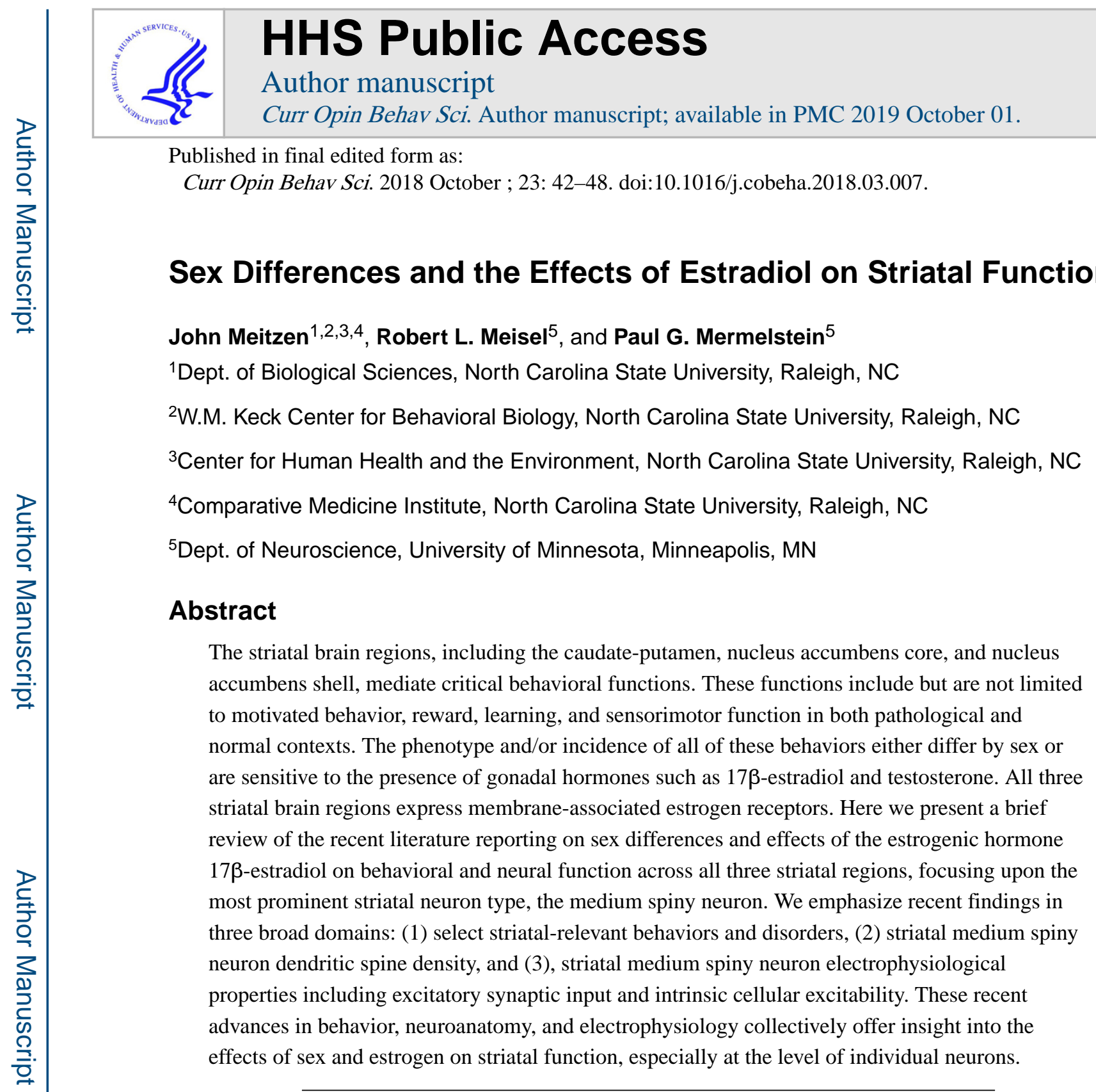

\title{
Prelude
}

Sex differences in the nervous system and behavior are most often thought to arise from patterns of gonadal hormone release early in development (organizational actions) or in adulthood (activational actions), along with chromosomal and epigenetic influences [1]. Given the key regulatory control by gonadal steroid hormones such as $17 \beta$-estradiol (estradiol) and testosterone, historically the prevailing strategy to localize the neural targets

Submitting Author: John Meitzen, Ph.D., Dept. of Biological Sciences, NC State University, 144 David Clark Labs, Campus Box 7617, Raleigh, NC, 27695-7617, jemeitze@ncsu.edu.

Conflict of Interest Statement

Nothing declared.

Publisher's Disclaimer: This is a PDF file of an unedited manuscript that has been accepted for publication. As a service to our customers we are providing this early version of the manuscript. The manuscript will undergo copyediting, typesetting, and review of the resulting proof before it is published in its final citable form. Please note that during the production process errors may be discovered which could affect the content, and all legal disclaimers that apply to the journal pertain. 
of hormone actions was to map the distribution of neurons that contained steroid hormone receptors (e.g., estrogen, progestin or androgen receptors) by autoradiography for intracellular accumulation of the respective steroid [2], immunocytochemistry for steroid receptor protein [3], or in situ hybridization to localize steroid receptor mRNA [4]. The rodent localization pattern for gonadal steroid receptors yielded a concentration of neurons located in the basal forebrain, including the hypothalamus, the hippocampus, and several other regions. These maps of steroid hormone receptor distributions commonly noted the sparse labeling of neurons in many other areas of the brain, including the striatum and its component regions [5]. The striatum is typically subdivided into the caudate-putamen (also called dorsal striatum), nucleus accumbens core, and nucleus accumbens shell. These three regions share neuron types, including the principal output neuron, the medium spiny neuron (MSN). However, they exhibit unique afferent and efferent projections, leading to differential involvement of striatal regions in functions such as sensorimotor activity, cognitive behaviors such as learning, motivated/reward related behaviors, and disorders such as depression, Parkinson's Disease and drug addiction.

Despite the relevance to critical neural functions and high-impact neurological disorders exhibiting sex differences and estradiol sensitivity in incidence and phenotype, the striatal regions were often a priori excluded from rodent studies of behavioral sex differences and related sites of hormones action. However, despite the sparse distribution of nuclear steroid hormone receptors in the striatum researchers found a host of striatal-mediated biochemical and behavioral endpoints that were either sexually dimorphic and/or hormonally regulated. These endpoints were later bolstered with other studies confirming the presence of estradiol [6] and membrane-associated estrogen receptor (ER) a, $\beta$, and GPER-1 in rodent striatal regions [7-13]. We present here a brief overview of the recent literature reporting sex differences and estrogen effects on striatal function, focusing on how sex and estradiol modulate behavior, dendritic spines, and electrophysiology.

\section{Sex, estradiol and behavior}

For everything known about the functions of the striatum, it is surprising that there are few contemporary studies investigating potential sex differences in striatal-mediated behaviors. One interesting area has explored sex commonalities in the activation of the nucleus accumbens following sexual behavior. In humans, the nucleus accumbens is activated during the presentation of visual sexual stimuli in both men and women [14]. More detailed mechanistic studies have been performed in male rats and female hamsters, and again similarities exist between males and females in these cross-species studies. For both male and female humans and rodents, engaging in sexual activity increases the release of dopamine in the nucleus accumbens as well as activating concomitant postsynaptic responses $[15,16]$. In female hamsters, for example, sexual experience facilitates the efficiency of future copulatory interactions [17] through dopaminergic signaling acting via a MAP kinase/ $\triangle$ FosB pathway $[15,18]$ to increase dendritic spine density [19]. It is well established that dopaminergic signaling in the striatum is generally augmented by increased estradiol exposure in rats, mice, and hamsters [20], including by contemporary research using tools such as optogenetics [21]. 
Sex differences in striatal behaviors have mostly been studied in the context of locomotor responses in rodents, with adult female rats generally more active than males [22]. Studelska and Beatty (1978) identified that increased open field activity in female compared to male rats was modulated by ovarian hormones, including estradiol, and was mediated by specific areas within caudate-putamen [23]. Similarly, sensorimotor activity varies across the rat estrous cycle, and implants of estradiol into the caudate-putamen improved sensorimotor performance [24]. A more recent study [25] has elegantly demonstrated the impact of estradiol, potentially of neural origin, on open field activity in rats, further confirming these early investigations. Sex differences in locomotor activity have most often been studied with respect to psychostimulant administration. Becker et al. (1982) demonstrated in rats that even after accounting for pharmacokinetic differences, females had greater locomotor responsiveness to amphetamine than did males [26]. This basic sex difference in response to psychomotor stimulants with females responding more strongly than males has been replicated across laboratories and psychostimulants [27]. Repeated administration of drugs triggers biochemical and structural plasticity in the nucleus accumbens which is associated with sensitized locomotor responses [28]. A possible mechanism for this phenomenon integrates several sources. First, drugs of abuse increase striatal MSN dendritic spine density to a greater degree in female than in male rats [29]. $\triangle F$ FosB is necessary for drugs of abuse to stimulate dendritic spine changes [30]. Cocaine has a greater effect on $\triangle F o s B$ accumulation in the nucleus accumbens core in female than male rats [31]. Finally, CREB is required for the induction of $\triangle F o s B$ [32], and cocaine stimulates phosphorylation of CREB to a greater extent in female than in male rats [33]. Collectively these studies build a framework for a mechanism through which drugs of abuse can act on the nucleus accumbens to produce greater locomotor responding in females compared to males. It would be valuable in the future to systematically investigate the cellular and molecular bases for sex differences in drug responsiveness and also other striatal-mediated disorders. For instance, Tourette syndrome and aspects of autism spectrum disorder show differential incidence and phenotype between men and women. Interneurons in the caudate-putamen have been implicated in these sex differences, and in an elegant paper Rapanelli and colleagues used a combination transgenic-viral strategy to ablate interneurons in both male and female mice [34]. Interestingly, interneuron depletion generated social behavior impairments, stereotypic behaviors, and anxiety-like behaviors in males but not females, recapitulating the sexuallydivergent phenotype of the relevant disorders in humans. Convergent with this research, the impact of genetic deletions associated with autism and other striatal-relevant disorders exhibit profound sex differences, again with increased vulnerability in male compared to female mice [35].

\section{Sex, estradiol, and dendritic spines}

One of the most striking effects of estrogens on brain plasticity encompasses the changes observed in neuron dendritic structures such as spines, including the predominant neuron type in the striatum, the MSN. The discovery that estradiol-exposure modulates striatal MSN dendritic spines came relatively later than for neurons in other brain regions. In 1990, Meisel and Luttrell first reported that within hamster ventromedial hypothalamus (VMH), two-day estradiol treatment resulted in an increase in neuronal dendritic length [36]. Based on the 
time point examined, as well as the VMH being densely populated with nuclear ER, there were no thoughts at the time that the mechanism by which estradiol affected dendritic length would be anything outside of classical signaling mechanisms. However, around the same time, estrogen-mediated increases in dendritic spine densities of rat hippocampal pyramidal neurons were discovered [37]. The hippocampus appeared to express fewer nuclear ERs than the hypothalamus, leaving the question open as to how estradiol modulated spine density. At the time, it was hypothesized that the mechanism by which estrogens affected hippocampal dendritic structure was through nuclear ER actions outside of this particular brain region indirectly impacting hippocampal neurotransmission leading to alterations in dendritic modeling. The discovery that ERs functionally couple to mGluRs, resulting in the ability of estradiol to directly activate of mGluR signaling [38], provided a clear and straightforward means by which estrogen signaling can alter dendritic structure [39]. Follow up studies have confirmed that in both rat hypothalamus and hippocampus, estradiol-induced changes in dendritic structure are due to ERa activation of mGluR1a signaling [40,41]. In rat hippocampus these changes in dendritic structure can be observed in as little as 30 minutes following hormone exposure [42].

These experiments provided a critical intellectual framework for investigations of estrogenic modulation of striatal MSN dendritic spines. Similar to the hippocampus and the hypothalamus, dendritic spine density and excitatory synapse number is increased in gonadintact proestrous female compared to male rat nucleus accumbens core MSNs [43-45]. The dendritic spine density of female nucleus accumbens core MSNs is sensitive to estradiol application, as demonstrated in ovariectomized rats and hamsters. In ovariectomized female rat and hamster nucleus accumbens core, where ERa is coupled to mGluR5, estradiolexposure produces a decrease in dendritic spine densities (Figure 1) [41,46]. This estradiolinduced decrease in spine density is in contrast to estradiol's actions upon hippocampal neurons. This difference in estrogen action upon spine density across brain regions may be due to a number of factors, but two possibilities include differences in the specific behaviors regulated by estradiol and the underlying molecular mechanism. Functionally, within rat nucleus accumbens core, alterations in dendritic structure and activation of mGluR5/ endocannabinoid signaling have been correlated with behavioral changes following drug exposure. Specifically, both estradiol potentiation of cocaine-induced locomotor sensitization and cocaine self-administration appear dependent on the ER/mGluR5 signaling mechanism [47,48]. Additional experiments have determined that ER/mGluR-associated decreases in dendritic spine density require mGluR-mediated endocannabinoid release, and activation of CB1 receptors [49]. In the nucleus accumbens shell, estrogen action on dendritic spine densities appears more complex. There is select evidence that estradiol increases the spine densities of nucleus accumbens shell MSNs though an ERa/mGluR1a mechanism, but this increase is not detected in every experiment [41]. Other hormones than estradiol may also modulate MSN dendritic structure in the nucleus accumbens shell, as long-term testosterone exposure decreased dendritic spine density in male rat MSNs [50].

Interestingly, the presence of ER/mGluR coupling does not guarantee estradiol-induced alterations in dendritic structure. Within rat and hamster caudate-putamen, where ERa is known to functionally couple to mGluR5, acute treatment of estradiol has no observable effect on dendritic spines $[41,46]$. This lack of acute estrogen effect is most likely due to an 
uncoupling of mGluR activity to dendritic plasticity in these neuronal populations [39]. It is unknown whether caudate-putamen dendritic spine density differs between male and female MSNs, although orbital frontal cortex to caudate-putamen projections have been proposed to be increased in adult female compared to male rats [51].

\section{Sex, estradiol and electrophysiology}

The first indication that striatal neuron electrophysiological properties were sensitive to estrogen and biological sex came in the early 1980s, when Arnauld and colleagues reported that the in vivo spontaneous action potential firing rates and concomitant sensitivity to dopamine increased after exposure to estradiol in adult ovariectomized female rat caudateputamen neurons [52]. Sex-specific differences in MSN excitability following exposure to estradiol was further established by Tansey and colleagues [53], who demonstrated that the in vivo firing rates of striatonigral MSNs in rat caudate-putamen of adult gonad-intact females exposed to estradiol, either naturally as part of the estrous cycle, or artificially via estradiol implants, was higher than those recorded from females in low estrogen states or males.

While these foundational experiments established that estradiol application sex-specifically regulates MSN in vivo excitability, little progress was made in identifying the underlying endocrine and electrophysiological mechanisms until the mid-1990s, when Mermelstein and colleagues demonstrated that estradiol acts on a membrane-associated ER to decrease L-type calcium channel currents in female but not male rat caudate putamen MSNs [11]. Over fourteen years later, the identity of the specific ER modulating calcium currents was determined to be membrane-associated ER $\beta$ [10]. These data indicate that estradiol can act directly upon striatal MSNs to change ion channel properties to potentially modulate intrinsic cellular excitability, in addition to potential estrogen actions upon excitatory synaptic transmission. Indeed, both intrinsic excitability and excitatory synaptic transmission are sensitive to estradiol and sex. A careful anatomical study by Forlano and Woolley detected an increased number of glutamatergic synapses in female compared to male rat nucleus accumbens core MSNs [44], indicating that the nucleus accumbens exhibits fundamental sex differences in afferent excitatory synaptic input. Supporting this model, increased mEPSC frequencies onto MSNs recorded from adult rat gonad-intact female compared to male nucleus accumbens core but not shell have been detected [45]. Building upon these findings, Cao and colleagues demonstrated that increased mEPSC frequency was present pre-puberty, was eliminated in females exposed to masculinizing/defeminizing doses of estradiol or testosterone as neonates, and accompanied by no sex differences in intrinsic excitability [54]. Thus, sex differences in excitatory synaptic signaling onto MSNs in the nucleus accumbens core are present long before adulthood, and likely induced by organizational hormone action.

Interestingly, increased excitatory synaptic input onto nucleus acumbens core MSNs is not generalizable to other striatal regions (Table 1). In pre-pubertal rat nucleus accumbens shell, there is no evidence that MSNs show sex differences in any electrophysiological property [55]. In pre-pubertal rat caudate-putamen, MSNs show no sex differences in mEPSC frequency, but do show increased intrinsic cellular excitability in female compared to male 
MSNs [56], providing a mechanism potentially underlying the seminal 1980s-era studies. Intriguingly, Tozzi and colleagues report that inhibition of the estradiol-producing enzyme aromatase blocks the induction of activity-dependent long term potentiation of excitatory inputs onto male rat caudate-putamen MSNs, although females were not tested [57]. Collectively, this body of work validates and extends the general theme that striatal neuron excitability varies by sex, but that the magnitude and mechanism (i.e., via changes in excitatory synaptic input or intrinsic cellular excitability) underlying these differences substantially differs by striatal region and developmental period. Finally, it is important to recognize that environmental and other factors could potentially induce or exacerbate sex differences in striatal neuron electrophysiology, including the effects of stress and exposure to drugs of abuse $[45,58,59]$.

\section{Epilogue}

The striatum is one of the most intensely studied regions in the mammalian brain. Indeed, over 10,000 papers featuring the keywords "striatum" and/or "nucleus accumbens" are listed in PubMed as published between January 2015 and December 2017. A similar PubMed search which also includes the keyword "sex" yielded only 360 papers. A search that used the keyword "estradiol" instead of "sex" produced only $~ 60$ papers. This is in contrast to the hippocampus. The keywords "hippocampus" and "estradiol" generated 250 papers and "hippocampus and sex" produced $\sim 800$ papers! These searches, along with our own difficulty finding manuscripts published since 2015 illustrate the infancy of our understanding regarding how estrogen and sex influences striatal function. The select advances discussed here build a strong foundation upon which to perform productive and fruitful studies. There are many possible directions of future studies, some of which include:

1. The mechanistic underpinnings of how sex and estradiol modulate striatal function, including the elucidation of the underlying ER.

2. The identity of the glutamatergic input elevated in female compared to male nucleus accumbens core.

3. The causal consequences of sex differences in MSN properties.

4. Actions of the estrous cycle and other hormones on adult striatal function.

5. The mechanisms underlying sex differences in incidence and phenotype of striatal-related disorders.

The striatal regions are rich, complex, and relevant to a wide range of behaviors and disorders. The data reviewed here indicate that sex and estrogen action should be considered relevant variables in striatal function. While this realization potentially complicates experimental design, addressing sex and estrogen action advances our comprehensive understanding of dynamic striatal function.

\section{Acknowledgments}

This work was supported by NIH DA013680 and NSF IOS 1256799 to RLM, NIH DA035008 to PGM and RLM, NIH DA41808 to PGM, and NIH MH109471 to JM. 


\section{References}

1. McCarthy MM, Wright CL, Schwarz JM. New tricks by an old dogma: Mechanisms of the organizational/activational hypothesis of steroid-mediated sexual differentiation of brain and behavior. Hormones and Behavior. 2009; 55(5):655-665. [PubMed: 19682425]

2. Pfaff D, Keiner M. Atlas of estradiol-concentrating cells in the central nervous system of the female rat. The Journal of Comparative Neurology. 1973; 151(2):121-158. [PubMed: 4744471]

3. Warembourg M, Jolivet A, Milgrom E. Immunohistochemical evidence of the presence of estrogen and progesterone receptors in the same neurons of the guinea pig hypothalamus and preoptic area. Brain research. 1989; 480(1-2):1-15. [PubMed: 2713643]

4. Lauber AH, Romano GJ, Pfaff DW. Gene expression for estrogen and progesterone receptor mrnas in rat brain and possible relations to sexually dimorphic functions. The Journal of steroid biochemistry and molecular biology. 1991; 40(1-3):53-62. [PubMed: 1958549]

5. Milner TA, Thompson LI, Wang G, Kievits JA, Martin E, Zhou P, McEwen BS, Pfaff DW, Waters EM. Distribution of estrogen receptor beta containing cells in the brains of bacterial artificial chromosome transgenic mice. Brain research. 2010; 1351(N/A):74-96. [PubMed: 20599828]

6. Morissette M, Garcia-Segura LM, Belanger A, Di Paolo T. Changes of rat striatal neuronal membrane morphology and steroid content during the estrous cycle. Neuroscience. 1992; 49(4): 893-902. [PubMed: 1436487]

7. Almey A, Filardo EJ, Milner TA, Brake WG. Estrogen receptors are found in glia and at extranuclear neuronal sites in the dorsal striatum of female rats: Evidence for cholinergic but not dopaminergic colocalization. Endocrinology. 2012; 153(11):5373-5383. [PubMed: 22919059]

8. Almey A, Milner TA, Brake WG. Estrogen receptors in the central nervous system and their implication for dopamine-dependent cognition in females. Hormones and behavior. 2015; 74(N/A): 125-138. [PubMed: 26122294]

9. Almey A, Milner TA, Brake WG. Estrogen receptor alpha and g-protein coupled estrogen receptor 1 are localised to gabaergic neurons in the dorsal striatum. Neuroscience letters. 2016 May; 27(622): $118-123$.

10. Grove-Strawser D, Boulware MI, Mermelstein PG. Membrane estrogen receptors activate the metabotropic glutamate receptors mglur5 and mglur3 to bidirectionally regulate creb phosphorylation in female rat striatal neurons. Neuroscience. 2010; 170:1045-1055. [PubMed: 20709161]

11. Mermelstein PG, Becker JB, Surmeier DJ. Estradiol reduces calcium currents in rat neostriatal neurons via a membrane receptor. J Neuroscience. 1996; 16(2):595-604.

12. Schultz KN, von Esenwein SA, Hu M, Bennett AL, Kennedy RT, Musatov S, Toran-Allerand CD, Kaplitt MG, Young LJ, Becker JB. Viral vector-mediated overexpression of estrogen receptoralpha in striatum enhances the estradiol-induced motor activity in female rats and estradiolmodulated gaba release. J Neuroscience. 2009; 29(6):1897-1903.

13. Bourque M, Morissette M, Di Paolo T. Raloxifene activates g protein-coupled estrogen receptor 1/akt signaling to protect dopamine neurons in 1-methyl-4-phenyl-1,2,3,6-tetrahydropyridine mice. Neurobiology of Aging. 2014; 35(10):2347-2356. [PubMed: 24726471]

14. Wehrum S, Klucken T, Kagerer S, Walter B, Hermann A, Vaitl D, Stark R. Gender commonalities and differences in the neural processing of visual sexual stimuli. The Journal of Sexual Medicine. 2013; 10(5):1328-1342. [PubMed: 23421466]

15. Meisel RL, Mullins AJ. Sexual experience in female rodents: Cellular mechanisms and functional consequences. Brain Research. 2006; 1126(1):56-65. [PubMed: 16978593]

16. Frohmader KS, Pitchers KK, Balfour ME, Coolen LM. Mixing pleasures: Review of the effects of drugs on sex behavior in humans and animal models. Hormones and Behavior. 2010; 58(1):149162. [PubMed: 20004662]

17. Bradley KC, Haas AR, Meisel RL. 6-hydroxydopamine lesions in female hamsters (mesocricetus auratus) abolish the sensitized effects of sexual experience on copulatory interactions with males. Behavioral Neuroscience. 2005; 119(1):224-232. [PubMed: 15727527] 
18. Hedges VL, Chakravarty S, Nestler EJ, Meisel RL. Delta fosb overexpression in the nucleus accumbens enhances sexual reward in female syrian hamsters. Genes, Brain, and Behavior. 2009; 8(4):442-449.

19. Staffend NA, Hedges VL, Chemel BR, Watts VJ, Meisel RL. Cell-type specific increases in female hamster nucleus accumbens spine density following female sexual experience. Brain Structure \& Function. 2014; 219(6):2071-2081. [PubMed: 23934655]

20. Becker JB. Sex differences in addiction. Dialogues in Clinical Neuroscience. 2016; 18(4):395-402. [PubMed: 28179811]

21*. Calipari ES, Juarez B, Morel C, Walker DM, Cahill ME, Ribeiro E, Roman-Ortiz C, Ramakrishnan C, Deisseroth K, Han MH, Nestler EJ. Dopaminergic dynamics underlying sexspecific cocaine reward. Nature Communications. 2017; 8:13877. Using a combination of chemogenic, electrochemical, and behavioral approaches, this study demonstrates that estradiol increases ventral tegmental area dopamine neuron activity to increase dopamine release in the nucleus accumbens, and modifies dopamine transporter (DAT) function. This enhances the affinity of cocaine for the DAT, further increasing dopamine concentrations and providing insight into sex differences in the responsiveness to drugs of abuse.

22. Beatty WW. Gonadal hormones and sex differences in nonreproductive behaviors in rodents: Organizational and activational influences. Hormones and Behavior. 1979; 12(2):112-163. [PubMed: 573741]

23. Studelska DR, Beatty WW. Open-field and avoidance behavior after neostriatal lesions in male and female rats. Journal of Comparative and Physiological Psychology. 1978; 92(2):297-311. [PubMed: 276532]

24. Becker JB, Snyder PJ, Miller MM, Westgate SA, Jenuwine MJ. The influence of estrous cycle and intrastriatal estradiol on sensorimotor performance in the female rat. Pharmacol Biochem Behav. 1987; 27(1):53-59. [PubMed: 3615546]

25*. Kokras N, Pastromas N, Papasava D, de Bournonville C, Cornil CA, Dalla C. Sex differences in behavioral and neurochemical effects of gonadectomy and aromatase inhibition in rats. Psychoneuroendocrinology. 2017; 87:93-107. Kokras and colleagues elegantly demonstrate the impact of estradiol, potentially of neural origin, on the behavior and catecholamine neurochemistry of males and females, providing a model study for assessing the intersection of sex and hormones on neural function. [PubMed: 29054014]

26. Becker JB, Robinson TE, Lorenz KA. Sex differences and estrous cycle variations in amphetamine-elicited rotational behavior. Eur J Pharmacol. 1982; 80(1):65-72. [PubMed: 7201404]

27. Segarra AC, Agosto-Rivera JL, Febo M, Lugo-Escobar N, Menendez-Delmestre R, Puig-Ramos A, Torres-Diaz YM. Estradiol: A key biological substrate mediating the response to cocaine in female rats. Hormones and Behavior. 2010; 58(1):33-43. [PubMed: 20026119]

28. Ferrario CR, Gorny G, Crombag HS, Li Y, Kolb B, Robinson TE. Neural and behavioral plasticity associated with the transition from controlled to escalated cocaine use. Biological Psychiatry. 2005; 58(9):751-759. [PubMed: 16098484]

29. Strong CE, Schoepfer KJ, Dossat AM, Saland SK, Wright KN, Kabbaj M. Locomotor sensitization to intermittent ketamine administration is associated with nucleus accumbens plasticity in male and female rats. Neuropharmacology. 2017; 121:195-203. [PubMed: 28479397]

30. Robison AJ, Vialou V, Mazei-Robison M, Feng J, Kourrich S, Collins M, Wee S, Koob G, Turecki G, Neve R, Thomas M, et al. Behavioral and structural responses to chronic cocaine require a feedforward loop involving deltafosb and calcium/calmodulin-dependent protein kinase ii in the nucleus accumbens shell. J Neuroscience. 2013; 33(10):4295-4307.

31. Sato SM, Wissman AM, McCollum AF, Woolley CS. Quantitative mapping of cocaine-induced deltafosb expression in the striatum of male and female rats. PloS One. 2011; 6(7):e21783. [PubMed: 21747956]

32. Vialou V, Feng J, Robison AJ, Ku SM, Ferguson D, Scobie KN, Mazei-Robison MS, Mouzon E, Nestler EJ. Serum response factor and camp response element binding protein are both required for cocaine induction of deltafosb. J Neuroscience. 2012; 32(22):7577-7584. 
33. Nazarian A, Sun WL, Zhou L, Kemen LM, Jenab S, Quinones-Jenab V. Sex differences in basal and cocaine-induced alterations in pka and creb proteins in the nucleus accumbens. Psychopharmacology (Berl). 2009; 203(3):641-650. [PubMed: 19052730]

34**. Rapanelli M, Frick LR, Xu M, Groman SM, Jindachomthong K, Tamamaki N, Tanahira C, Taylor JR, Pittenger C. Targeted interneuron depletion in the dorsal striatum produces autism-like behavioral abnormalities in male but not female mice. Biological Psychiatry. 2017; 82(3):194203. Both Tourette syndrome and aspects of autism spectrum disorder show differential incidence and phenotype between males and females. Interneurons in the caudate-putamen have been implicated in these disorders, and in an elegant paper Rapanelli and colleagues used a combination transgenic-viral strategy to ablate interneurons in both males and females. Interneuron depletion generated social behavior impairments, stereotypic behaviors, and anxietylike behaviors in males but not females, recapitulating the sexually-divergent incidence of the relevant disorders in humans. [PubMed: 28347488]

35. Grissom NM, McKee SE, Schoch H, Bowman N, Havekes R, O’Brien WT, Mahrt E, Siegel S, Commons K, Portfors C, Nickl-Jockschat T, et al. Male-specific deficits in natural reward learning in a mouse model of neurodevelopmental disorders. Molecular Psychiatry. 2017 Epub ahead of print.

36. Meisel RL, Luttrell VR. Estradiol increases the dendritic length of ventromedial hypothalamic neurons in female syrian hamsters. Brain Research Bulletin. 1990; 25(1):165-168. [PubMed: 2207703]

37. Gould E, Woolley CS, Frankfurt M, McEwen BS. Gonadal steroids regulate dendritic spine density in hippocampal pyramidal cells in adulthood. J Neuroscience. 1990; 10(4):1286-1291.

38. Boulware MI, Weick JP, Becklund BR, Kuo SP, Groth RD, Mermelstein PG. Estradiol activates group i and ii metabotropic glutamate receptor signaling, leading to opposing influences on camp response element-binding protein. J Neuroscience. 2005; 25(20):5066-5078.

39. Gross KS, Brandner DD, Martinez LA, Olive MF, Meisel RL, Mermelstein PG. Opposite effects of mglur1a and mglur5 activation on nucleus accumbens medium spiny neuron dendritic spine density. PloS One. 2016; 11(9):e0162755. [PubMed: 27618534]

40. Christensen A, Dewing P, Micevych P. Membrane-initiated estradiol signaling induces spinogenesis required for female sexual receptivity. J Neuroscience. 2011; 31(48):17583-17589.

41*. Peterson BM, Mermelstein PG, Meisel RL. Estradiol mediates dendritic spine plasticity in the nucleus accumbens core through activation of mglur5. Brain Structure \& Function. 2015; 220:2415-2422. This study employed DiI labeling and confocal microscopy to elucidate that estradiol-induced increased in dendritic spine density in female nucleus accumbens core neurons is mediated via mGluR5 activation. Given that nucleus accumbens core dendritic spines and mGluR5 are implicated in drug addiction, these data provide an important clue regarding the mechanism underlying sex-specific responses to drugs of abuse. [PubMed: 24878822]

42. Tuscher JJ, Luine V, Frankfurt M, Frick KM. Estradiol-mediated spine changes in the dorsal hippocampus and medial prefrontal cortex of ovariectomized female mice depend on erk and mtor activation in the dorsal hippocampus. J Neuroscience. 2016; 36(5):1483-1489.

43. Wissman AM, May RM, Woolley CS. Ultrastructural analysis of sex differences in nucleus accumbens synaptic connectivity. Brain, Structure, and Function. 2012; 217(2):181-190. [PubMed: 21987050]

44. Forlano PM, Woolley CS. Quantitative analysis of pre- and postsynaptic sex differences in the nucleus accumbens. The Journal of Comparative Neurology. 2010; 518(8):1330-1348. [PubMed: 20151363]

45. Wissman AM, McCollum AF, Huang GZ, Nikrodhanond AA, Woolley CS. Sex differences and effects of cocaine on excitatory synapses in the nucleus accumbens. Neuropharmacology. 2011; 61:217-227. [PubMed: 21510962]

46. Staffend NA, Loftus CM, Meisel RL. Estradiol reduces dendritic spine density in the ventral striatum of female syrian hamsters. Brain, Structure, and Function. 2011; 215(3-4):187-194. [PubMed: 20953625]

47. Martinez LA, Gross KS, Himmler BT, Emmitt NL, Peterson BM, Zlebnik NE, Foster Olive M, Carroll ME, Meisel RL, Mermelstein PG. Estradiol facilitation of cocaine self-administration in female rats requires activation of mglur5. eNeuro. 2016; 3(5) ENEURO.0140-0116.2016. 
48. Martinez LA, Peterson BM, Meisel RL, Mermelstein PG. Estradiol facilitation of cocaine-induced locomotor sensitization in female rats requires activation of mglur5. Behavioural Brain Research. 2014; 271:39-42. [PubMed: 24893316]

49. Peterson BM, Martinez LA, Meisel RL, Mermelstein PG. Estradiol impacts the endocannabinoid system in female rats to influence behavioral and structural responses to cocaine.

Neuropharmacology. 2016; 110:118-124. [PubMed: 27266915]

50. Wallin-Miller K, Li G, Kelishani D, Wood RI. Anabolic-androgenic steroids decrease dendritic spine density in the nucleus accumbens of male rats. Neuroscience. 2016; 330:72-78. [PubMed: 27238893]

51. Bayless DW, Daniel JM. Sex differences in myelin-associated protein levels within and density of projections between the orbital frontal cortex and dorsal striatum of adult rats: Implications for inhibitory control. Neuroscience. 2015; 300:286-296. [PubMed: 26002313]

52. Arnauld E, Dufy B, Pestre M, Vincent JD. Effects of estrogens on the responses of caudate neurons to microiontophoretically applied dopamine. Neuroscience Letters. 1981; 21(3):325-331. [PubMed: 7219879]

53. Tansey EM, Arbuthnott GW, Fink G, Whale D. Oestradiol-17 beta increases the firing rate of antidromically identified neurones of the rat neostriatum. Neuroendocrinology. 1983; 37(2):106110. [PubMed: 6684218]

54*. Cao J, Dorris DM, Meitzen J. Neonatal masculinization blocks increased excitatory synaptic input in female rat nucleus accumbens core. Endocrinology. 2016; 157(8):3181-3196. This study established that sex differences in nucleus accumbens core medium spiny neuron excitatory input exist prepuberty, as illustrated by increased mEPSC frequency in female compared to male neurons. Increased mEPSC frequency was eliminated in females exposed to masculinizing/ defeminizing doses of estradiol or testosterone as neonates, and is accompanied by no sex differences in intrinsic cellular excitability. This indicates that sex differences in excitatory synaptic signaling onto MSNs in the nucleus accumbens core are present long before adulthood, and likely induced by organizational hormone action. [PubMed: 27285859]

55. Willett JA, Will TR, Hauser CA, Dorris DM, Cao J, Meitzen J. No evidence for sex differences in the electrophysiological properties and excitatory synaptic input onto nucleus accumbens shell medium spiny neurons. eNeuro. 2016; 3(1) pii: ENEURO.0147-0115.2016.

56. Dorris DM, Cao J, Willett JA, Hauser CA, Meitzen J. Intrinsic excitability varies by sex in prepubertal striatal medium spiny neurons. Journal of Neurophysiology. 2015; 113(3):720-729. [PubMed: 25376786]

57. Tozzi A, de Iure A, Tantucci M, Durante V, Quiroga-Varela A, Giampa C, Di Mauro M, Mazzocchetti P, Costa C, Di Filippo M, Grassi S, et al. Endogenous 17beta-estradiol is required for activity-dependent long-term potentiation in the striatum: Interaction with the dopaminergic system. Front Cell Neurosci. 2015; 9(192)doi: 10.3389/fncel.2015.00192

58. Brancato A, Bregman D, Ahn HF, Pfau ML, Menard C, Cannizzaro C, Russo SJ, Hodes GE. Subchronic variable stress induces sex-specific effects on glutamatergic synapses in the nucleus accumbens. Neuroscience. 2017 May; 350(14):180-189. [PubMed: 28323008]

59. Hodes GE, Pfau ML, Purushothaman I, Ahn HF, Golden SA, Christoffel DJ, Magida J, Brancato A, Takahashi A, Flanigan ME, Menard C, et al. Sex differences in nucleus accumbens transcriptome profiles associated with susceptibility versus resilience to subchronic variable stress. J Neuroscience. 2015; 35(50):16362-16376. 


\section{Highlights}

1. Striatal-mediated behaviors are sensitive to estrogen and vary by sex.

2. Sex and estrogen modulate striatal medium spiny neuron dendritic spine density.

3. Sex and estrogen influence striatal medium spiny neuron electrophysiological properties.

4. Sex and estrogen effects upon medium spiny neuron properties varies by striatal region. 


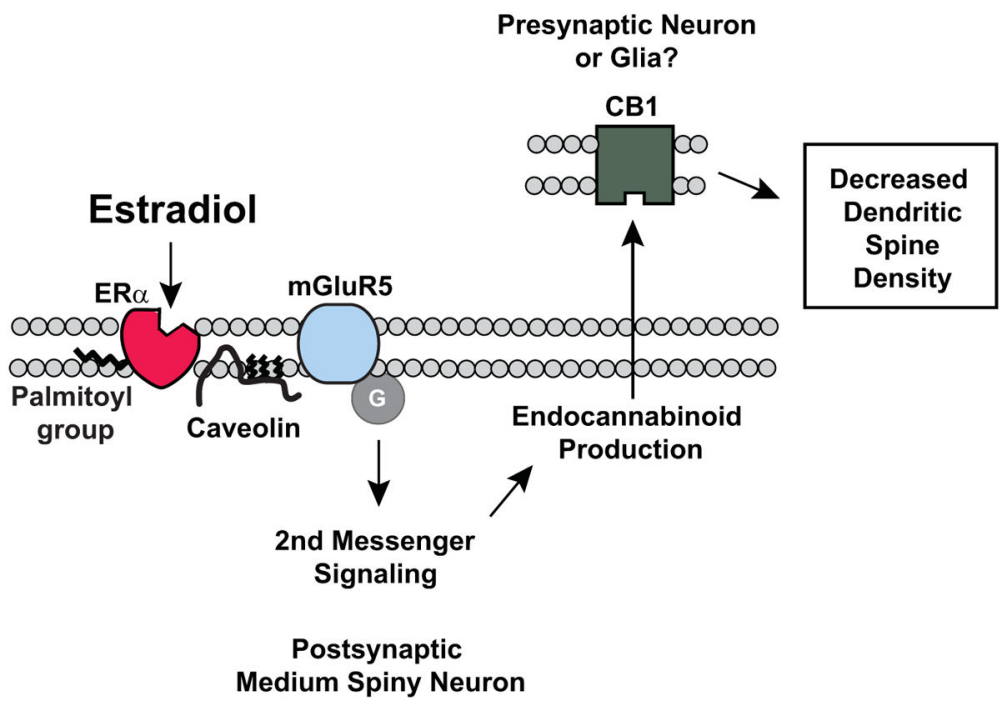

Figure 1.

Schematic of estradiol/ERa/mGluR/endocannabinoid signaling pathways mediating estradiol-induced decreases in dendritic spine density in female nucleus accumbens core medium spiny neurons. These ERa/mGluR signaling microdomains on medium spiny neurons are likely organized by caveolin and palmitoylation, and trigger second messenger pathways to trigger endocannabinoid production. These endocannabinoids activate CB1 receptors, ultimately inducing increased densities of dendritic spines on the postsynaptic medium spiny neuron. The location of the CB1 receptors could be either upon presynaptic terminals or astrocytes, a question which should be addressed by future research.

Abbreviations: ERa, estrogen receptor a; mGluR, metabotropic glutamate receptor; G, Gprotein; CB1, Cannabinoid receptor type 1. 


\section{Table 1}

Development of sex differences in medium spiny neuron electrophysiological properties varies by striatal region.

\begin{tabular}{|c|l|c|c|c|}
\hline Electrophysiological Property & Developmental Stage & Caudate-Putamen & Nucleus Accumbens Core & Nucleus Accumbens Shell \\
\hline \multirow{2}{*}{ Intrinsic Cellular Excitability } & Pre-puberty & $q>\sigma^{*}$ & $q=\sigma^{*}$ & $q=\sigma^{*}$ \\
\cline { 2 - 5 } & Adult & $? \%$ & $?$ & $?$ \\
\hline \multirow{2}{*}{ Excitatory Synaptic Input } & Pre-puberty & $q=\sigma^{*}$ & $\%>\sigma^{*}$ & $q=\sigma^{*}$ \\
\cline { 2 - 5 } & Adult & $? \%$ & $q>\sigma^{*}$ & $q=\sigma^{*}, \#$ \\
\hline
\end{tabular}

Notes: Sex differences in medium spiny neuron electrophysiological properties vary by striatal region. Medium spiny neurons show increased intrinsic excitability in female compared to male caudate-putamen, but no sex differences in excitatory synapse properties. In contrast, medium spiny neurons in the nucleus accumbens core show increased excitatory synapse number in females compared to males. This is indicated by both neuroanatomical studies and in electrophysiological measures such as the frequency of miniature excitatory postsynaptic currents.

$\%$ due to alterations in intrinsic cellular excitability and/or excitatory synaptic input.

* Gonad-intact animals, females not sorted by estrous cycle stage.

\# Most but not all nucleus accumbens shell literature shows no evidence of sex differences in excitatory synaptic input in control animals. 